\title{
El museo como instrumento educativo hacía la diversidad: la experiencia del Museo Judío de Chile ${ }^{1}$
}

\section{The museum as an educational instrument towards diversity: the experience of the Jewish Museum of Chile}

\author{
Deborah Roitman, PH.D \\ Museo Interactivo Judío de Chile \\ Debyroitman@gmail.com
}

Los museos pueden ser un sistema de comunicación al servicio de la educación y de la promoción cultural. Actúan como educadores en el ámbito de lo no formal, apoyo escolar y vínculo para la educación permanente. Presentamos acá el caso del Museo Interactivo Judío de Chile (MIJ) una institución educativa no formal que a través de sus dos recorridos - Historia judía y Holocausto, otorga capacitación a profesores y desarrolla recursos educativos on line y también presenciales. Dirigido especial aunque no exclusivamente a público estudiantil, jóvenes entre los 15 y los 18 años, su propósito es mostrar la falacia de los prejuicios y estereotipos que frecuentemente se tienen acerca de los judíos.

El MIJ es un intrumento cuyo objetivo es inculcar y transmitir a su público la importancia que debe asignárseles a los Derechos Humanos, los valores de respeto, diversidad, tolerancia religiosa y la multiculturalidad existentes en toda sociedad. Así, cada uno de estos valores, además del conocimiento adquirido (la educación), intentan prevenir y evitar ideas antisemistas entre la población chilena.

Palabras claves: Museo, educación no formal, comunicación, multiculturalidad, judaísmo, historia judía.

\section{SUMMARY:}

Museums can be a communication system to the education and cultural promotion service. They act as educators in the field of non-formal, school support and link for continuing education. At the same time the museums can even operate as extensions of the classroom or as pedagogical tools for formal education; they are a supplement where the museums may be essential in the formal educational system partners. We will see the case of the Museum interactive Jew of Chile (MIJ), which, being an institution within the scope of the non-formal education, carries out direct interventions in the classroom, trains teachers, develop educational resources for teachers and for the students, according to its compulsory subjects. Considered that this non-formal education sometimes can be so and more effective than formal teaching in schools. The aim of this non-profit

\footnotetext{
${ }^{1}$ Este artículo es parte de la ponencia expuesta en las XIX Jornadas sobre Alternativas Religiosas en América Latina, realizadas en Santiago de Chile, 14 a 17 de noviembre de 2018, cómo parte del grupo "Diferentes miradas desde la diversidad religiosa" (GT5) coordinado por Deborah Roitman y Ana María Tapia-Adler.
} 
institution is to support teaching in the school curriculum in relevant issues such as tolerance, human rights, diversity and multiculturalism.

$\mathrm{R}$

Keywords: Museum, non-formal education, communication, multicultural, Judaism, Jewish history.

\section{Introducción}

La educación es parte esencial de los nuevos cometidos de los museos alrededor del mundo. El Museo Interactivo Judío de Chile (MIJ), institución dentro del ámbito de la educación no formal, lleva a cabo intervenciones directas en los salones de clase, capacita al profesorado, desarrolla recursos educativos para docentes y para los estudiantes, acordes a las asignaturas obligatorias del curriculum de estudios. Su quehacer es importante en la medida que la educación no formal, en ocasiones, puede ser tan y más efectiva que la enseñanza formal de las escuelas. El objetivo de esta institución, sin fines de lucro, es busca apoyar-en la enseñanza de la currícula escolar en temas tan relevantes como la tolerancia, los Derechos Humanos, la diversidad y la multiculturalidad.

\section{Nuevo concepto y nuevas funciones de los museos}

Según el Consejo Internacional de Museos $(\mathrm{ICOM})^{2}$ “"[u]n museo es una institución permanente, sin fines de lucro, al servicio de la sociedad y abierta al público, que adquiere, conserva, estudia, expone y difunde el patrimonio material e inmaterial de la humanidad con fines de estudio, educación y recreo".

El museo es un espacio al servicio de la comunidad toda, y debe contribuir a su desarrollo y a la aceptación de la diversidad en la sociedad. Del mismo modo debe generar y permitir un espacio de reflexión, de apropiación por parte de los sujetos donde al "contar la historia, esta sea entendida con cruces y heterogeneidades. Por esto es que debemos concebir al museo "como un campo activo en la creación de nuevos sentidos sociales, sobre la base del reconocimiento y el respeto a la diversidad"” (Batallan). ${ }^{3}$

Hace varios años que los museos del mundo se han ido acomodando al nuevo canon que refiere a estas instituciones como centros culturales vivos y como puntos de encuentro de la comunidad, en contrapartida al museo tradicional visto como elitista, autoritario y de puertas cerradas. Se ha producido un cambio en la concepción de los museos. Ha habido un tránsito entre el museo-templo centrado en la difusión de sus colecciones, a un museo abierto, accesible a las demandas de su público habitual y a las de nuevos públicos; abierto a nuevas formas expositivas y diversos relatos

\footnotetext{
${ }^{2}$ Articulo 3 sección 1 de los estatutos, adoptados durante la 22 Conferencia General de Viena en el año 2007. Texto aprobado el 24 de agosto de 2007 en Viena, Austria. En: https://icom.museum/es/actividades/normas-ydirectrices/definicion-del-museo/

${ }^{3}$ Bosch, El Museo Como Educador . P. 1.
} 
posibles, a la renovación de su acervo y de sus prácticas. ${ }^{4}$ En la actualidad se considera que el museo no puede ser solamente lugar de contemplación, sin ningún tipo de impacto sobre el individuo, sino debe ser capaz de conjugar ocio, enseñanzas y cuestionamientos. Los museos son constituyen espacios extraordinarios donde los visitantes pueden tener un amplio rango de experiencias. ${ }^{5}$

La nueva museología pone de manifiesto que el museo no es solo para investigadores y eruditos, sino-centre también un centro de enseñanza y ocio $^{6}$ y su función educativa es la de tener la capacidad - por medio de la comunicación-de transmitir conocimientos, valores y experiencias en diversas áreas-Puesto que el museo es un espacio de comunicación per sé, se puede considerar a éste como un medio de comunicación al igual que la radio, la televisión y los medios interactivos.

En la actualidad los museos desarrollan una serie de actividades comunicativas, entre las que destacan talleres, ciclos, charlas, conferencias, seminarios. No obstante, sus muestras aunque continúan siendo las actividades más reconocidas ${ }^{7}$, los museos son un sistema de comunicación al servicio de la educación y de la promoción cultural; es decir se han convertido tanto en un medio como en un fin de la acción cultural. ${ }^{8}$

El papel de la museografía como técnica expositiva al servicio de la divulgación, se orienta hacía el mensaje, la enseñanza y el impacto que se quiere provocar en el público asistente. La función básica del museo es ubicar a su audiencia dentro de su mundo para que tome conciencia de su problemática como hombre individuo y hombre social. El museo debe ser y brindar un espacio de reflexión sobre la identidad en la diversidad. ${ }^{9}$

La educación es un proceso que tiende a capacitar al individuo para actuar conscientemente frente a nuevas situaciones de la vida, aprovechando la experiencia anterior y teniendo en cuenta la integración, la continuidad y el progreso social. La educación se establece como el pilar fundamental para el crecimiento de una sociedad ${ }^{10}$ y considerando que el proceso de enseñanza-

\footnotetext{
${ }^{4}$ Islas, Uruguay. Museo abierto: Recuperación de otras historias/historias otras en los relatos posibles de la Nación. Pp. 22-23 y Arellano, Perú. El Museo Nacional de Arqueología, Antropología e Historia como espejo de la historia y sociedad peruana. P. 30.

${ }^{5}$ Hein, Learning in the Museum. P. 2.

${ }^{6}$ Notario, El público en el museo actual. Reflexiones sobre la Nueva Museología y las masas. P. 201.

${ }^{7}$ Mellado, Museos y educación o las diversas lecturas educativas del museo. P. 2.

${ }^{8}$ Notario, El público en el museo actual. Reflexiones sobre la Nueva Museología y las masas. P. 194.

${ }^{9} I d$, p. 22.

${ }^{10}$ Mellado, Museos y educación o las diversas lecturas educativas del museo p. 2. Bosch, El Museo Como Educador. P. 2.
} 
aprendizaje, abarca mucho más que el ámbito escolar, se reconocen tres situaciones educativas: ${ }^{11}$

1. Educación formal - tomada como sinónimo de situación educativa escolar. Se considera el aprendizaje ofrecido normalmente por un centro de educación o formación, con carácter estructurado (según objetivos didácticos, duración o soporte) y que concluye con una certificación. El aprendizaje formal es intencional desde la perspectiva del alumno.

2. Educación informal - es aquella que enseña contenidos, es formadora de hábitos, de valores, de experiencias y habilidades, fuera de las instituciones creadas específicamente con ese fin. Es espontánea más que intencional. ${ }^{12} \mathrm{Su}$ aprendizaje se obtiene en las actividades de la vida cotidiana relacionadas con el trabajo, la familia o el ocio. No está estructurado (en objetivos didácticos, duración ni soporte) y normalmente no conduce a una certificación.

3. Educación no formal - aprendizaje que no es ofrecido por un centro de educación o formación y normalmente no conduce a una certificación. No obstante, tiene carácter estructurado (en objetivos didácticos, duración o soporte). El aprendizaje no formal es intencional desde la perspectiva del alumno. ${ }^{13}$ Se encuentra presente fundamentalmente en instituciones que cuentan con una orientación educativa establecida en sus principios rectores, pero que sin embargo no corresponden al ámbito de la educación formal y donde el "educando" no es sólo el estudiante, sino también todo el "público objetivo", al cual se le ofrece una variada gama de información jerarquizada en base a sus requerimientos.

Es justamente la educación no formal, el modelo de enseñanza que hace de hilo conductor con el propósito de entender la función de los museos en general y del Museo Interactivo Judío de Chile en particular.

\section{El museo cómo referente educativo}

El capital cultural, considerado como lo que se aprende fuera del ámbito escolar, es tan importante, o incluso más crucial, que el plan de estudios formal que siguen los niños en las escuelas. Películas, museos, eventos culturales, historias familiares y narrativas nacionales constituyen fuentes abundantes de capital cultural que pueden ayudar a los alumnos a cubrir las lagunas de conocimiento que dejan las escuelas en ocasiones. Por otro lado, se debe de considerar que este caudal cultural puede transmitir asimismo sesgos, puntos de vista excesivamente simplificados, reivindicaciones políticas, información incorrecta o conceptos erróneos, capaces de ejercer un notable impacto en el modo en que las personas entienden e interpretan este complejo pasado. ${ }^{14}$

\footnotetext{
${ }^{11}$ Mellado, Museos y educación o las diversas lecturas educativas del museo p. 2. Bosch, El Museo Como Educador. P. 2.

${ }^{12}$ https://deconceptos.com/ciencias-sociales/educacion-informal

${ }^{13}$ http://ineditviable.blogspot.com/2012/07/educacion-formal-informal-y-no-formal.html

${ }^{14}$ UNESCO Educación sobre el Holocausto y prevención del genocidio, una guía para la formulación de políticas. 2013. París, Francia. P. 50.
} 
Esto puede conducir a los prejuicios sociales dentro de sociedades multiculturales. Hacerle frente a esos fenómenos que llevan a la discriminación negativa es parte de la educación.

Los centros conmemorativos y los museos pueden ser socios esenciales del sistema educativo formal. En muchos países, tales instituciones se han multiplicado y se encuentran fuertemente implicadas en las iniciativas nacionales emprendidas para reforzar la importancia de la materia. En ocasiones, esto ha dado lugar a la creación de redes regionales o nacionales que combinan sectores de la educación no formal y formal de un modo que amplía las capacidades de los profesores, y brinda a los alumnos oportunidades de aprendizaje innovadoras y alternativas. ${ }^{15}$ Es necesario que se pueda capitalizar lo aprendido fuera del entorno del aula. ${ }^{16}$

Las organizaciones que realizan actividades de educación no formal pueden complementar la labor de las escuelas. Un gran número de tales instituciones llevan a cabo intervenciones directas en las aulas, imparten formación al profesorado, elaboran materiales para el aprendizaje de alumnos y docentes, organizan viajes de estudio a museos, centros conmemorativos y sitios históricos.

Los museos, dentro del ámbito de la educación no formal, son capaces de transmitir conocimientos, valores y experiencias en diversas áreas, por medio de la comunicación. Esto lleva a reconocer a los museos como extensiones de la sala de clases o como herramientas pedagógicas para la educación formal. ${ }^{17}$ Uno de los objetivos de la dimensión educativa del museo es poder complementar los contenidos vistos en el aula por los estudiantes de los distintos establecimientos educacionales del país. Son vistos como interlocutores indispensables en la tarea de estimular, complementar y sostener la labor efectuada en el contexto escolar porque bien utilizados devienen en un componente impactante en la experiencia de aprendizaje al ofrecer espacios significativos para la reflexión.

En la medida en que los objetos que se exhiben son portadores de información y potencialmente significativos para el aprendizaje y el afianzamiento del conocimiento, la pregunta es ¿cómo hacer uso de este potencial para que el público que asiste al museo, cualquiera que éste sea, viva una experiencia realmente significativa de aprendizaje? Al acceder al espacio físico del sitio, o a artefactos tangibles que cuentan las historias de aquellos que experimentaron el pasado, los visitantes se pueden conectar con el acontecimiento de una manera diferente que al leer un libro de texto o ver una película porque la innovación de nuevos métodos de expresiones y tecnologías en los museos de hoy, en muchos casos deja atrás las exposiciones poco dinámicas y sin espacio a la reflexión característica de los museos de antaño.

Como base del aprendizaje experiencial, la consideración de significados sociales, políticos, religiosos o estéticos del artefacto cultural remite a un rico repertorio de aspectos humanos que

\footnotetext{
${ }^{15}$ UNESCO Educación sobre el Holocausto y prevención del genocidio, una guía para la formulación de políticas. 2013. París, Francia.

${ }^{16}$ Bosch, El Museo Como Educador. P. 2.

${ }^{17}$ Hein, Learning in the Museum. P. 7.
}

Cuadernos Judaicos ISSN: 07188749

N³6 -Diciembre 2019 
puede ayudar a los visitantes a comprender el mundo que les rodea y a asumirse en él. ${ }^{18}$

Existe una variedad de formas y expresiones que se pueden crear y utilizar en los museos con el propósito de educar - de forma lúdica -, e impactar a una audiencia diversa. ${ }^{19}$ Puede ser a través del diseño de material y talleres didácticos; elaboración de material multimedia; construcción de una web del museo que incluya una sección educativa; elaboración de material de diseño y coleccionismo; diseño de visitas guiadas, incluido programas específicos para público con necesidades educativas especializadas; desarrollar actividades lúdicas como herramientas para el aprendizaje, entre otras.

\section{La diversidad, la universalidad y el público}

De acuerdo a la idea sobre el cambio del museo en su rol educativo y de exposición abierta, la actividad museológica actual sólo puede justificarse social y culturalmente en función de su destinatario: la audiencia. Es por ello que si, en efecto, educar supone una de las funciones primordiales del museo, esto apunta a que el enfoque educativo de éste se centre, a grandes rasgos, en la relación que guarda la institución con la población en lo general y la relación que existe entre el objeto exhibido y el espectador en lo particular.

Las exhibiciones buscan dialogar con su público, ya no sólo desde un esquema contemplativo visual, sino mucho más interactivo, invitando a desarrollar todos los sentidos, desde la vista, el oído y el tacto hasta el movimiento del cuerpo, y el olfato. ${ }^{20}$ Sin duda todo ello se traduce en un aprendizaje dirigido y con códigos científicos establecidos por la museografía. Adquiere importancia acá el monitor/guía, quién orienta al público/alumnos hacía una nueva modalidad de aprendizaje. Este personaje, es quién, a través del uso de los objetos en exhibición, puede hablar de conceptos, valores, tradiciones, ideas, descubrimientos científicos, sistemas sociopolíticos, herencia cultural, expresión estética, etc. de forma lúdica, amena y clara. Es quién no solo describe sino que instruye buscando un impacto en su público.

En la actualidad la función social debiera ser la piedra angular de la existencia del museo y, por ello, es que la dimensión educativa de éste es determinante, sobre todo a partir de las nuevas tendencias museológicas que centran su interés a favor de los espectadores y su posición esencial en el quehacer museístico. ${ }^{21} \mathrm{El}$ aprendizaje ahora requiere una interacción entre el alumno/público y su entorno.

\footnotetext{
${ }^{18}$ Fraile y Alonso, La función educativa del museo, su importancia y sus implicaciones en la tendencia museológica actual.

${ }^{19}$ Olaia Fontal Merillas, op. cit., p. 29 en: Fraile y Alonso, La función educativa del museo, su importancia y sus implicaciones en la tendencia museológica actual. Bosch, El Museo Como Educador. Pp. 2-3.

${ }^{20}$ Mellado, Museos y educación o las diversas lecturas educativas del museo. P. 2.

${ }^{21}$ Fraile y Alonso, La función educativa del museo, su importancia y sus implicaciones en la tendencia museológica actual. En Universalidad y variedad en la estética y el arte. Volumen 4.
} 
La forma de ver y entender la vida de diferentes comunidades de personas, condiciona totalmente la manera en que cada una difunde y asimila información. Esta diversidad humana, con su forma particular de entender la realidad, hay que tenerla muy en cuenta a la hora de programar el contenido de la exposición en el museo. Si nos centramos en las diferentes creencias religiosas o la ausencia de ellas, comprobaremos que son un hecho condicionante a la hora de proponer dicho contenido en el museo. Hay que tener muy en cuenta esa diversidad, aunque esta sea totalmente diferente a la de uno mismo, con distintos puntos de vista. ${ }^{22}$

A modo de ejemplo, los museos de carácter religioso, de toda clase de creencias, tienen que tener muy en cuenta la diversidad de percepciones. No es lo mismo que jóvenes musulmanes vayan a visitar una exposición sobre arte sacro cristiano románico; o que jóvenes católicos visiten una exposición sobre arte islámico; o que lo haga una persona agnóstico o de religión judía. Por esto es que una exposición de esta naturaleza necesita estar construida sobre la base de una gran delicadeza pedagógica y didáctica. Debe considerar los muchos niveles de percepción de las diferentes culturas que la visitan: agnósticos, cristianos, ateos, judíos; todo el espectro de formas de entender la interpretación de la diversidad religiosa y cultural.

La diversidad cultural genera una reflexión abierta sobre la forma que los museos adoptan para exponer sus contenidos. Por ello es que actualmente los contenidos de los museos deben ser dirigidos a partir de la universalidad necesaria para ser valorados por todo el espectro de visitantes posible. El museo se debe de ir adaptando a la demanda del nuevo público consumidor de cultura y educación.

En la actualidad uno de los públicos más numeroso y con cada vez mayor peso, es el público escolar. Este público enfatiza la didáctica como el elemento que más ha buscado su sitio en el museo. ${ }^{23}$ Se debe considerar que las excursiones colegiales recalan en los museos, y que son una oportunidad valiosísima para generar impacto en una audiencia joven que traen el futuro en su mirada. $^{24}$

Es sabido que el público de los museos se extiende mucho más allá del escolar. Se suman toda audiencia interesada en el conocimiento que cruza los límites de la educación formal y estructurada en aulas de clases. Aquí entran, a modo de ejemplo, los estudiantes universitarios, profesores, académicos, grupos religiosos y público en general. ${ }^{25}$

\footnotetext{
${ }^{22}$ https://evemuseografia.com/2015/09/16/museos-cultura-y-religion/

${ }^{23}$ Notario, El público en el museo actual. Reflexiones sobre la Nueva Museología y las masas. P. 196.

${ }^{24}$ Ibídem , p. 196

${ }^{25}$ Islas, Uruguay. Museo abierto: Recuperación de otras historias/historias otras en los relatos posibles de la Nación. P. 20.
} 


\section{Museo Interactivo Judío de Chile: educación hacia la multiculturalidad ${ }^{26}$}

Desde el comienzo de la diáspora, hace casi dos mil años, los judíos, como pueblo y como religión, han estado deambulando, adaptándose e involucrándose con las sociedades donde se asentaron. Este intercambio activo resultó en una variedad muy enriquecedora a nivel cultural e incluso en los objetos tradicionales y ceremoniales más simples. Hoy, cientos de museos en todo el mundo comparten la responsabilidad de proteger y celebrar la variedad y tradición del estilo de vida judío y los objetos judaicos que se han generado a lo largo de la historia. El siglo XX ha sido testigo del establecimiento de museos que apuntan a señalar la importancia y la profundidad de la historia judía, desde sus inicios hasta la actualidad, para todo público.

De acuerdo a Dorfman y Horenczyk, ${ }^{27}$ el propósito del perfil etno-cultural (PEC) ${ }^{28}$ fue ser la brújula que orientó la creación y el desarrollo del Museo Interactivo Judío de Chile, donde lo esencial es que el visitante experimente una vivencia emocional profunda, que lo conecte con su historia personal y familiar, conexión ésta que puede vincularlo con su propia cultura o bien, puede contribuir a establecer puentes desde su propia identidad cultural hacia otras. A fin de favorecer la comprensión, el PEC debe alternar entre el gran relato general, y los pequeños relatos particulares que pueden articular con historias personales, y permitir al visitante profundizar su experiencia y motivarlo a explorar sus propias fuentes étnicas y familiares, a la luz de sus raíces o bien de las señas identitarias de otras culturas. De esta forma se valida en cierto modo un enfoque de educación multicultural que se orienta al diálogo entre identidades y culturas diferentes.

Así es como, bajo la línea de la diversidad cultural y social, el Museo Interactivo Judío de Chile abrió sus puertas en $2014 .^{29}$ Es un museo cuya muestra se enfoca principalmente en la historia del pueblo judío y el Holocausto.

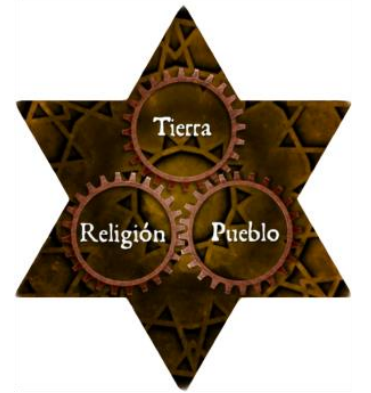

Religión, tierra y pueblo son las tres directrices que dirigen y convergen a lo largo de todo el recorrido de Historia Judía. Pueblo y religión van entrañablemente unidos y caminan en paralelo. En ocasiones esta interconexión es extremadamente difícil de diferenciar y por esto es que en

\footnotetext{
${ }^{26}$ Dorfman \& Horenczyk, La dimensión ideológico-identitaria en un proyecto multicultural de educación museal

${ }^{27}$ Id. p. $14-15$

${ }^{28}$ Según estos autores, el perfil etnocultural considera que lo relevante es la posibilidad del visitante de construir "identidad", en el caso de aquellos que pertenecen al mismo grupo identitario, y "empatía", en el caso de aquellos que no pertenecen a ese grupo. En este ámbito, palabras como valores, identidad, cultura y continuidad son frecuentes en su narrativa.

${ }^{29}$ El Museo Interactivo Judío de Chile se fundó gracias a la donación de una familia, que en homenaje a su padre, quisieron honrarlo con un proyecto educativo. El Museo Interactivo Judío de Chile forma parte del Consejo Mundial de Museos - ICOM desde 2015.
} 
la exposición del MIJ ha sido necesario mantener un equilibrio entre la historia del pueblo con su religión, el judaísmo. ${ }^{30}$

El MIJ se destaca por su voluntad de respetar y explicar de manera accesible lo intangible, sin demagogia, exhibiendo y mostrando racionalmente las diferentes formas que ha asumido la religión judía a lo largo del tiempo y en los diferentes lugares del mundo donde el pueblo judío se ha asentado. La religión es reconocida como un fenómeno típico de la sociedad humana, con un papel extremadamente importante, incluso dentro de un mundo contemporáneo y el judaísmo no es la excepción.

Para este proyecto, el equipo encargado de su creación de contenido se preguntó: “...cuál es el rol de un museo educativo, y en este caso, el de un museo educativo interactivo y judío en el marco de una sociedad en que la comunidad judía es ampliamente minoritaria". ${ }^{31}$ Intentando dar respuestas, los contenidos fueron desarrollados bajo un concepto profesional multidisciplinario. ${ }^{32}$ La obra a realizarse era un concepto inédito en Latinoamérica: la creación de un museo que apelara tanto a las emociones como a la intelectualidad, y ofreciera respuesta a preguntas tan esenciales como complejas: ¿Quiénes son los judios? ¿Cómo una cultura sobrevive 3000 años?¿Qué se necesita para mantener la identidad nacional de un pueblo? ¿Qué pasó durante el Holocausto?

Su contenido se despliega mediante el uso de tecnología digital, permitiendo al visitante aprender a través de la interacción, tanto a nivel intelectual como emocional, acerca de los distintos aspectos de la identidad e historia del pueblo judío.

El MIJ se puso como objetivo contribuir a que las futuras generaciones chilenas puedan ir conociendo quiénes son los judíos y formen sus propias apreciaciones y opiniones acerca de sus creencias y tradiciones. Como se señaló cuando el museo fue inaugurado: "El museo es una oportunidad para que los chilenos nos conozcan y puedan formar sus propias apreciaciones y opiniones con el fin de evitar que las mentiras y propagandas sean la fuente de persecución de nuestro pueblo o de cualquier otra minoría. En ese sentido, esperamos que el museo sea usado como tal." 33

Esto último se refiere a querer mostrar al público quiénes son los judíos, combatir la ignorancia y los prejuicios ante esta pequeña comunidad insertada en la sociedad chilena. En una etapa donde el

\footnotetext{
${ }^{30}$ En la antigüedad y la Edad Media, la etnia y religión se encontraban en una conexión indisoluble y era la religión el criterio al ser judío y no-judío. Con la Modernidad, viene la crisis de identidad en el Judaísmo donde caben los cuestionamientos: ¿Existe una única definición del Judaísmo? ¿Son los judíos una comunidad religiosa o nacional o una tradición cultural? Surgen formas diferentes de expresión del ser judío y se enfoca al Judaísmo como un fenómeno de carácter heterogéneo.

${ }^{31}$ Dorfman \& Horenczyk, La dimensión ideológico-identitaria en un proyecto multicultural de educación museal.

${ }^{32}$ Centro Melton de Educación Judía de la Universidad Hebrea de Jerusalem y la empresa Orpan de Israel, con el apoyo del Centro de Estudios Judaicos de la Universidad de Chile (CEJ), Fundación Memoria Viva y el Circulo Israelita de Santiago (CIS), junto a muchas personas que aconsejaron desde sus experticias.

${ }^{33}$ http://mij.cl/blog/noticias/inauguracion-museo-interactivo-judio-de-chile
} 
pluralismo es inherente en la sociedad chilena, es deber aceptar a todas las minorías que son parte de la sociedad y poder respetarse y convivir en armonía.

Dentro de sus metas, el MIJ busca el encuentro entre la identidad judía y la sociedad chilena, movilizados por el desafío de transmitir los valores judíos a un público no conocedor de esta cultura. Como institución de educación no formal, intenta a través de la educación, derribar los muros de la indiferencia y desarmar prejuicios que pueden conducir a la discriminación y a la violencia, en el peor de los casos. Aboga por un Chile que valore cada vez más la riqueza inmaterial que aporta la convivencia entre culturas.

\section{Recorridos y recursos educativos del MIJ}

Son dos las modalidades básicas que se despliegan en el museo desde su creación: el recorrido de (1) Historia Judía, el recorrido de (2) Holocausto, que incluyen recursos educativos trasversales a temas universales como la discriminación y los genocidios.

\section{1) Recorrido Historia Judía}

La historia, como hilo conductor, tiene como propósito explicar ordenadamente las correspondencias y relaciones de los hechos sobresalientes del pasado, básicamente con fines educativos, ya a-finales del siglo XX los museos con muestras relacionadas a la historia, comienzan a caracterizarse por una organización expositiva que muestran los marcos cronológicos no como verdades absolutas, sino como estímulos de reflexión y entendimiento en sus diferentes aspectos. No copia de la realidad sino que presenta una síntesis verosímil y mutable, con apoyos tecnológicos y lenguajes que cada generación hace inteligibles, al concepto de verdad como categoría teórica, no como categoría moral. ${ }^{34}$

A través del recorrido de Historia Judía se difunde e instruye la historia del pueblo judío en contexto y en paralelo con la historia universal; así como su inserción y adaptación a la cultura occidental. Este recorrido se caracteriza por desplegar su contenido mediante el uso de tecnología digital interactiva, que permiten al visitante aprender de manera participativa, tanto a nivel cognitivo como emocional. En el tránsito del relato histórico específico-del pueblo judío, se hizo una selección de relatos que pudieran exponer la historia de modo que resultara entretenido para su público, por lo que el museo debió mezclar la tradición con la contemporaneidad.

Son cuatro salas multimedia que recorren tres mil años de tradición de un pueblo inserto en la historia universal que van desde los inicios del pueblo con Abraham hasta la fundación del Estado de Israel. ${ }^{35}$ Se expone la interacción del pueblo judío con diferentes civilizaciones y el aporte en

\footnotetext{
${ }^{34}$ Rueda Smithers, Salvador. La Museografía como Historiografía, p. 9.

${ }^{35}$ La visita misma se inicia con un video donde se expone el relato bíblico: los comienzos del pueblo hebreo y el monoteísmo, hasta su entrada a la tierra de Canaán. Al término del video se avanza hacia las instalaciones del MIJ donde se transita por una breve exposición sobre los judíos de Chile a través de los hitos que han marcado a este grupo minoritario dentro de territorio chileno. Se continúa con el Corredor Bíblico, donde se enfatiza la época fundacional del pueblo hebreo. Se procede a ingresar a las salas sobre distintos periodos de la historia judía donde se reproducen objetos de época, líneas cronológicas que cruzan los eventos del período
} 
todas las áreas donde se ha insertado. Se retratan patriarcas, reyes, hombres y mujeres que dieron forma a la identidad del pueblo judío. En cada sala se enfatiza los valores universales de la sociedad occidental de hoy.

En este recorrido se gatillan interesantes debates y cuestionamientos acerca de lo que significa ser chileno y pertenecer a un colectivo específico y por qué es importante valorar la identidad cultural de una minoría. El respeto y valor por la diversidad cultural es parte esencial de la formación ciudadana; y sólo es posible alcanzarlo abriéndose a conocer los distintos grupos que conforman la sociedad chilena.

\section{2) Recorrido de Holocausto}

El segundo recorrido es una experiencia audiovisual acerca del Holocausto. Aquí se transmite de manera precisa y contundente los contenidos históricos y morales centrales de este oscuro pasaje de la historia mundial, además de conformarse como un memorial para honrar a los caídos en el Holocausto y dignificar a los sobrevivientes. El trayecto se presenta a través de documentales, dilemas éticos interactivos y testimonios de sobrevivientes del Holocausto que hicieron de Chile su patria. Se intenta comprender cómo la intolerancia, la discriminación y la indiferencia pueden desencadenar enormes tragedias y genocidios.

Durante la visita se exponen contenidos de educación cívica que se desarrollan en el contexto de lo ocurrido en la Segunda Guerra Mundial, desde una mirada valórica y de responsabilidad social. Se plantean dilemas éticos y prácticos que se vivieron dentro de los guetos, y la resistencia frente a las atrocidades que tuvieron que sufrir durante este periodo.

El Holocausto, -hito histórico y hasta el día de hoy paradigma de un genocidio y violación de los derechos humanos-, es mostrado a través de diversas formas. El mensaje que pretende entregarse es la necesidad de profundizar en este acontecimiento histórico que excede las fronteras de la historia judía y atañe a la humanidad toda. Se le otorga relevancia a las víctimas, humanizando de este modo la tragedia histórica con la biografía de quienes la sufrieron y sobrevivieron para $\operatorname{contar}^{36}$ y se menciona a los Justos entre las Naciones (personas no judías que arriesgaron su vida para salvar a quienes estaban siendo perseguidos y ejecutados por pertenecer a un grupo particular o por pensar distinto) que mostraron el rostro humano de la guerra y la destrucción.

La historia del Holocausto - o de cualquier otro caso de genocidio o atrocidad masiva - suscita a menudo cuestiones éticas complejas, y remueve fuertes emociones, lo que puede resultar difícil de gestionar tanto para los monitores, los educadores, y los alumnos. Este auténtico desafío puede complicarse aún más en los países que han de afrontar un legado de conflictos ya que en muchos

en Chile y en el mundo e innovadores recursos audiovisuales. Cada una de estas salas refleja un periodo histórico junto a un personaje representativo de la época: la época Antigua con el rey David, la época del Segundo Templo con Rabí Akiva, la Edad Media con Maimónides y finalmente la Edad Moderna con Herzl. El recorrido finaliza en la sinagoga de la Comunidad Israelita de Santiago. Para mayor información entrar al link http://mij.cl/mi-visita/preparacion-recorrido-historia-judia.

36 http://impresa.lasegunda.com/2018/09/03/A/IG3F09VH/all 
casos, la enseñanza sobre el Holocausto cuestionará ciertas narrativas históricas que posiblemente sigan prevaleciendo en algunos segmentos de la sociedad. A la vez que, el antisemitismo y/o el racismo latentes entre ciertos alumnos y educadores pueden obstruir una educación apropiada sobre el Holocausto u otros casos de genocidio y barbaries masivas.

Finalmente, considerando la enseñanza del Holocausto dentro de la contemporaneidad del pasado, se debe de visualizar las causas e identificar las alertas hoy en día de procesos que tienen raíces similares. El mensaje que se quiere transmitir es que está en nuestras manos el impedir que las violaciones a los derechos humanos y la discriminación ocurran, incluso en nuestros días. Es así cómo, el examinar la historia en un contexto de prevención de atrocidades, permite al público no solo comprender mejor cómo-es posible que ocurra un genocidio, sino también considerar cómo podrían sus propias acciones prevenir, atenuar y responder a los prejuicios y a la discriminación en la actualidad.

Ambos recorridos son dirigidos por monitores capacitados, cuya labor es facilitar la visita del público de modo que se aprovechen de la mejor forma los recursos didácticos y tecnológicos que se ofrecen.

Es importante señalar que el relato que se narra en el MIJ presenta aspectos críticos que despiertan controversia $^{37}$, y que el visitante deberá confrontarse también con estos aspectos de la historia. En este sentido, otro desafío es que los guías de ambos recorridos acepten confrontarse con estas situaciones controversiales. ${ }^{38}$

\section{Recursos educativos}

El MIJ, como parte de su misión educativa, busca apoyar en los objetivos de la educación formal de los colegios de Chile. El personal del Museo trabaja en estrecha colaboración con las autoridades educativas locales para garantizar que las exposiciones y los programas combinen y complementen el plan de estudios de la escuela, establecidas por el Ministerio de Educación de Chile (Mineduc).

Debido a que no siempre es posible trasladar a los estudiantes a las instalaciones del museo, el MIJ pone a disposición una serie de recursos educativos, ${ }^{39}$ en principio ideados para que el docente los desarrolle en el aula como preparación de la visita o para detenerse en algún aspecto de lo aprendido luego de recorrer el Museo. La página web del Museo contiene un listado de vocabulario básico (glosarios), recomendaciones de películas para contextualizar la visita y material sobre los periodos que se ven en el Museo, con preguntas para investigar y debatir en grupo. Gran parte de los recursos educativos están divididos por recorrido, aunque algunos pueden servir para ambos.

\footnotetext{
${ }^{37}$ Por ejemplo, el relato de la muerte de Jesús o el actual conflicto en Medio Oriente. Dorfman \& Horenczyk, La dimensión ideológico-identitaria en un proyecto multicultural de educación museal distancia, p. 11.

${ }^{38} I d$, p. 11.

${ }^{39}$ Para ver con detalle los recursos educativos del MIJ entrar al link http://mij.cl/recursos
} 
Para el tema del Historia Judía ${ }^{40}$ los recursos educativos van enfocados a las líneas del tiempo, a cada una de las salas del Museo y un glosario con terminologías importante de conocer para aprovechar mejor este recorrido. Para el tema del Holocausto ${ }^{41}$ los recursos educativos son muy variados. Los temas que se tocan se vinculan directamente con la educación sobre los Derechos Humanos, el respeto a las minorías y a la convivencia en la diversidad, temas que actúan como directrices auxiliares tanto para alumnos como para los docentes. ${ }^{42}$ Por esta razón se han desarrollado programas de educación adecuados y complementarios a los encuadres curriculares en las asignaturas de Historia, Geografía y Ciencias Sociales, Lenguaje y Plan de Formación Ciudadana.

Es importante la humanización y personificación de lo acontecido durante el Holocausto, para ello el MIJ utiliza testimonios de sobrevivientes del Holocausto ${ }^{43}$, entre ellos 82 testimonios de sobrevivientes $^{44}$ que lograron huir de la guerra y comenzar una nueva vida en Chile. ${ }^{45}$

Uno de los recursos educativos que ha tenido muy buena recepción entre los docentes de Media ha sido la actividad titulada La pirámide del odio. ${ }^{46}$ Este programa dota a los alumnos, a partir de $7^{\circ}$ Básico, con los valores, conocimientos y competencias basadas en los Derechos Humanos, la justicia social y la diversidad, que a su vez fomentan el respeto hacia esos principios y permiten que los estudiantes lleguen a ser ciudadanos responsables. Proporciona a los alumnos las competencias y la oportunidad para hacer realidad esos derechos y obligaciones, con miras a promover un mundo y un futuro mejor para todos.

Todo lo anterior se presenta con el claro objetivo de promover la diversidad y la convivencia en una sociedad pluralista y multicultural y poniendo en alerta de cómo los prejuicios y la discriminación 40 Para ver con detalle los recursos educativos referentes al recorrido de Historia Judía entrar al link
http://mij.cl/recursos/recorrido-historia-judia

41 Para ver con detalle los recursos educativos referentes al recorrido de Holocausto entrar al link http://mij.cl/recursos/holocausto

${ }^{42}$ La enseñanza sobre el Holocausto es una actividad que promueve las Naciones Unidas. En Educación sobre el Holocausto y la prevención del genocidio. Una guía para la formulación de políticas, P. 15.

${ }^{43}$ http://mij.cl/blog/noticias/se-suman-82-testimonios-de-sobrevivientes-chilenos-del-holocausto-la-muestra http://mij.cl/blog/noticias/sobrevivientes-del-holocausto-se-convierten-en-maestros-para-una-sociedad-mashumana

${ }^{44}$ Los sobrevivientes relatan en una grabación (entrevista) su vida anterior a la guerra, lo que les sucedió durante la guerra y su vida posterior en Chile. Algunos de estas personas hoy en día dan su testimonio de forma oral a los colegios que lo requieran.

45 El MIJ cuenta con estos testimonios, los cuales son parte de la colección de la USC Shoah Foundation, organismo que ha logrado recolectar más de 53,000 testimonios de sobrevivientes del Holocausto a lo largo de todo el mundo, así como de otros genocidios como el de Armenia, Ruanda y Guatemala.

46 http://mij.cl/recurso/la-piramide-del-odio 
pueden conducir a una violencia que puede llegar a la decisión del exterminio de un grupo humano, provocando un genocidio.

\section{Público/audiencia del MIJ}

El estudio de público es un fenómeno cuyo desarrollo es bastante reciente en América Latina. Este análisis se refiere al proceso de obtención de conocimientos sistemáticos de los visitantes de museos con el propósito de incrementar y utilizar dicho conocimiento para planificar actividades. ${ }^{47} \mathrm{El}$ público del MIJ consiste básicamente en alumnos (a partir de los 14 años) de escuelas y el cuerpo docente ¿Por qué este énfasis en la etapa escolar? Las generaciones adultas, aquellos que son los padres de la audiencia objetivo del MIJ, ya cuentan con ideas fijas y preconcebidas muy difíciles de cambiar, muchas veces basadas en prejuicios y experiencias de sus propias realidades. Los niños y jóvenes están en una etapa de sus vidas donde todavía están construyendo su propia realidad e identidad; y es justo aquí cuando se puede transmitir a las nuevas generaciones información y enseñanzas para que ellos puedan ir creando, desde el respeto y la convivencia, sus propios universos, desde el conocimiento y no desde los prejuicios y estereotipos creados.

Siguiendo esta línea de ideas, el MIJ pretende lograr un impacto en la joven audiencia para que desde estos nuevos conocimientos, puedan construir un mundo más justo, inclusivo y respetuoso. El desafío es crear condiciones para que un visitante acepte la invitación de participar, opinar; asumir un rol, imaginar situaciones desde otra perspectiva, sin eludir las problemáticas controversiales. ${ }^{48}$ Lo que se quiere lograr en ambos recorridos en las jóvenes generaciones es una experiencia educativa cuya novedad es tanto el contenido como el formato: se propicia el debate y se ejerce la habilidad de observar una problemática desde distintos puntos de vista, además de ofrecer el espacio para que los visitantes despejen dudas sobre el pueblo judío, el judaísmo y el Holocausto.

\section{Logros, tareas pendientes y desafíos}

A lo largo de los 5 años de existencia, el MIJ ha tenido muchos logros, así como tareas pendientes por cumplir. Lo importante es saber reconocer los errores para entender cómo mejorar y lograr un mayor rendimiento e impacto en la audiencia objetivo. Finalmente, están los nuevos desafíos considerando logros y tareas que perfeccionar.

A continuación una tabla que señala de manera específica lo anterior detallando los logros y haciendo ver las tareas pendientes a realizar.

\footnotetext{
\begin{tabular}{|l|c|c|}
\hline \multicolumn{2}{|c|}{ Logros } & Tareas pendientes \\
\hline Varios colegios de la región metropolitana ya & Llegar a los colegios regionales, fuera del área de \\
\hline
\end{tabular}

${ }^{47}$ Cita de Eloisa Perez Santos en la American Association of Museums (AMM) en Estudio de Público Visitante.

${ }^{48}$ Calvo \& Stáffora, ¿Transmitir, comunicar, mediar? la experiencia de difusión en un museo antropológico.sêpip. 6.
} 
incorporan la visita al MIJ como parte de sus actividades extra programáticas fijas o como parte integrante del Plan de Formación Ciudadana.

En 5 años se ha llegado a más de 40.000 personas; más de 25.000 estudiantes; más de 1.600 docentes y más de 7.000 visitas público general

Se han desarrollado recursos educativos con contenido complementario y de profundización en el sitio web y en redes sociales, para las asignaturas de la currícula escolar.

Se desarrollan recursos didácticos en idioma español dentro de programa de IWitness, en alianza con la USC Shoah Foundation

Se han establecido vínculos y realizado actividades con el Museo de la Memoria y los Derechos Humanos, Villa Grimaldi, Columbia Global Center, Departamento de DDHH de Carabineros de Chile y Consejo Internacional de Museos y la UNESCO. ${ }^{49}$

Se ha logrado ampliar la información acerca del Holocausto en los libros de texto de la asignatura de Historia, Geografía y Ciencias Sociales del Mineduc. $^{50}$
Santiago, debido a las distancias

Evaluar el impacto de las visitas en dos aspectos:

Lograr la repetición de la visita por parte del colegio.

Conocer el impacto y el aprendizaje de la visita en su público

En cuanto a los recursos:

Lograr claridad si estos recursos son ocupados.

En caso de ser empleados cabe cuestionarse si son de utilidad para el objetivos asignado apoyo para la visita y complemento de una asignatura escolar determinada).

Buscar conocer si estos recursos son revisados y utilizados

Lograr establecer contacto con otras
organizaciones..

Es deseable el lograr estar presentes en la página web del Mineduc como referente del tema del Holocausto en Chile.

\section{A modo de conclusión}

Si la educación es una de las funciones primordiales en la actualidad de la mayoría de los museos en el mundo, el MIJ no es la excepción. Su misión en términos formativos, tanto a través de sus exhibiciones permanentes como de sus recursos educativos y actividades, es la de poder causar impacto en su público transmitiendo el mensaje de la multiculturalidad, de la convivencia a partir de la aceptación de la diversidad social y cultural del Chile de hoy y del mundo en su totalidad.

Para el logro de su objetivo El MIJ, está consciente que debe considerar la relación de demanda y oferta. Esto significa conocer y entender cuáles son las necesidades de la audiencia y, a partir de allí, evaluar qué y cómo entregó su mensaje y si este tuvo impacto en los cinco años de vida que este año cumple el Museo. Se hace necesario un estudio permanente de las necesidades de la gente,

${ }^{49} \mathrm{http}: / / \mathrm{mij} . \mathrm{cl} / \mathrm{blog} /$ noticias/mij-se-consolida-y-proyecta-crecimiento

50 Entre 2010 y 2017 el libro contenía una breve mención del Holocausto sin explicación alguna; en el texto del 2018 son 5 las páginas de referencia a este evento, mencionando conceptos claves como Holocausto, genocidio, propaganda nazi antisemita, 6 millones de víctimas judías. El texto hace especial hincapié en las victimas y los Justos de las Naciones, e instruye a los docentes a trabajar estos temas dentro del marco de la diversidad y la toma de decisiones. 
contemplando la realidad socioeconómica y cultural y encontrar y utilizar los instrumentos y formas de medición adecuados con el propósito de conocer si los esfuerzos que se hacen hoy en día por lograr instruir a los jóvenes causan el impacto deseado.

Los museos deben existir también para conciliar y acercar a las personas con distintas formas de comprender la vida. Entender el origen de las cosas es muy importante para aprender a valorarlas, y el museo es pieza clave en ese proceso de enseñar el porqué, el cómo y el dónde. Por lo tanto está consciente que su orientación considera que la educación y la verdad son fuente de conocimiento para evitar los prejuicios, la discriminación y el odio. El conocimiento bien difundido será bien asimilado y a eso lo llamamos cultura, que su vez es el antídoto más efectivo contra la violencia.

El mensaje que el MIJ difunde es, pues,-muy concreto: todos somos iguales.

\section{BIBLIOGRAFÍA:}

Arrelano Hoffmann, Carmen. Perú. El Museo Nacional de Arqueología, Antropología e Historia como espejo de la historia y sociedad peruana. En Revista Museos Publicación De La Subdirección Nacional De Museos - DIBAM- Chile. \#30, Año 2011. Pp. 25-34. En: http://www.museosdibam.cl/628/articles-22075_archivo_01.pdf

Bosch, Sebastián. El Museo Como Educador. Retrieved from: Http://Emuseoros.Wm.Com.Ar/ En: Https://Www.Academia.Edu/5973619/EL_MUSEO_COMO_EDUCADOR

Calvo, Silvia L. \& Stáffora, Verónica (2013). ¿Transmitir, Comunicar, Mediar? La Experiencia de difusión en un museo antropológico.

En: http://sedici.unlp.edu.ar/bitstream/handle/10915/41749/Documento_completo.pdf?sequence=1

Dorfman, M. \& Horenczyk, G. (2014). La Dimensión Ideológico-Identitaria En Un Proyecto Multicultural De Educación Museal. RED, Revista De Educación A Distancia. Número 41. Número Monográfico Sobre "Interculturalidad En El Nuevo Paradigma Educativo". 15 De Junio De 2014. Consultado El (Dd/Mm/Aaaa) En: Http://Www.Um.Es/Ead/Red/41 Recuperado a partir de https://revistas.um.es/red/article/view/23448

Fraile Martín, Isabel y Alonso Rivera, Adriana. (2013). "La función educativa del museo, su importancia y sus implicaciones en la tendencia museológica actual”. En Universalidad y Variedad en la Estética y el Arte. Volumen 4. Coordinadores: Ramón Patiño Espino José Antonio Pérez Diestre. Colección La Fuente, Benemérita Universidad Autónoma De Puebla, Puebla, México 
Hein, George E. (1998). Learning In The Museum. En: Https://Books.Google.Cl/Books/About/Learning In The Museum.Html?Id=Omxoiamu$\underline{\text { GEC } \& \text { Redir_Esc }=Y}$

Islas, Adriana (2011). Uruguay. Museo abierto: recuperación de otras historias/historias otras en los relatos Posibles de la nación. En La Revista No. 30, 2011. Pp. 15-24. Museos Históricos y de Memoria: ¿Qué Pasa En Chile? En: http://www.museosdibam.cl/628/articles-22075_archivo_01.pdf

Mellado González, Leonardo. Museos y Educación o las Diversas Lecturas Educativas del Museo. En: Http://Www.Museohistoriconacional.Cl/618/Articles-9480 Archivo 14.Pdf

Ramos Galicia, Y. \& Jiménez Rugerio, A. Estudio de Público Visitante . En: :http://s3.amazonaws.com/academia.edu.documents/31591649

Rueda Smithers, Salvador (2011). México. La Museografía Como Historiografía. En La Revista No. 30, 2011. Pp. 5-10. Museos Históricos y de Memoria: ¿Qué Pasa En Chile? En: http://www.museosdibam.cl/628/articles-22075_archivo_01.pdf

Notario Sánchez, Álvaro ( 2018). El Público En El Museo Actual. Reflexiones Sobre La Nueva Museología Y Las Masas. En De Arte. Revista De Historia Del Arte 2018 No 17. Universidad De León, Castilla, España, Pp. 191-204. ISSN Electrónico: 2444-0256

Educación sobre el Holocausto y la prevención del genocidio. Una guía para la formulación de políticas (2017). Organización De Las Naciones Unidas Para La Educación, La Ciencia Y La Cultura (UNESCO). Francia. En: Https://Formacionciudadana.Mineduc.Cl/WpContent/Uploads/Sites/46/2018/03/Educación-Sobre-El-Holocausto-Y-La-Prevención-DelGenocidio-UNESCO.Pdf

Entrevista A Michael Berenbaum Por Codner, K. (3/09/2018) Http://Impresa.Lasegunda.Com/2018/09/03/A/IG3F09VH/All

Museos, Cultura y Religión Https://Evemuseografia.Com/2015/09/16/Museos-Cultura-Y-Religion/

UNESCO Educación Sobre el Holocausto y Prevención del Genocidio, Una Guía Para la Formulación de Políticas. 2013. París, Francia.

\section{Sitios propios de internet:}

https://icom.museum/es/actividades/normas-y-directrices/definicion-del-museo/ https://deconceptos.com/ciencias-sociales/educacion-informal http://ineditviable.blogspot.com/2012/07/educacion-formal-informal-y-no-formal https://melton.huji.ac.il Http://Mij.Cl/Blog/Noticias/Inauguracion-Museo-Interactivo-Judio-De-Chile wWw.cis.cl 
Http://Mij.Cl/Blog/Noticias/Emotiva-Colocacion-De-La-Primera-Piedra-Del-Museo

Http://Fundacionhispanojudia.Org/Museo-Judio-De-Espana/Museo-Judios-Mundo/

Http://Fundacionhispanojudia.Org/Actividades/

Http://Www.Hughlevin.Com/Catalog/Jewmuseums.Html

Http://Mij.Cl/Blog/Noticias/Sobrevivientes-Del-Holocausto-Se-Convierten-En-Maestros-Para-Una-

Sociedad-Mas-Humana

Http://Mij.Cl/Blog/Noticias/Mij-Se-Consolida-Y-Proyecta-Crecimiento

Http://Mij.Cl/Blog/Noticias/Inauguracion-Museo-Interactivo-Judio-De-Chile

Http://Mij.Cl/Blog/Noticias/Mij-Se-Consolida-Y-Proyecta-Crecimiento

Http://Mij.Cl/Blog/Noticias/Mij-Profundiza-Asociacion-Con-La-Fundacion-Shoah

Http://Mij.Cl/Blog/Noticias/Museo-Interactivo-Judio-De-Chile-Aplaude-Plan-De-Formacion-

Ciudadana-Y-Derechos Http://Mij.Cl/Blog/Noticias/Promoviendo-El-Debate-Como-Metodologia-

Para-El-Aprendizaje-Significativo 